http://revistaseletronicas.pucrs.br/ojs/index.php/aviation doi): http://dx.doi.org/10.15448/2179-703X.2014.1.19903

\title{
Entrevista com Agustin Folgueira
}

\section{Interview with Agustin Folgueira}

\author{
Rafael Reimann Baptista ${ }^{1}$, Camila Freitas de Oliveira², Bianca Garrido Dias², Thais Russomano \\ Centro de Microgravidade da Pontificia Universidade Católica do Rio Grande do Sul - PUCRS, Porto Alegre, RS. \\ ${ }_{2}^{2}$ Assessoria de Comunicação Social da Pontificia Universidade Católica do Rio Grande do Sul - PUCRS, Porto Alegre, RS.
}

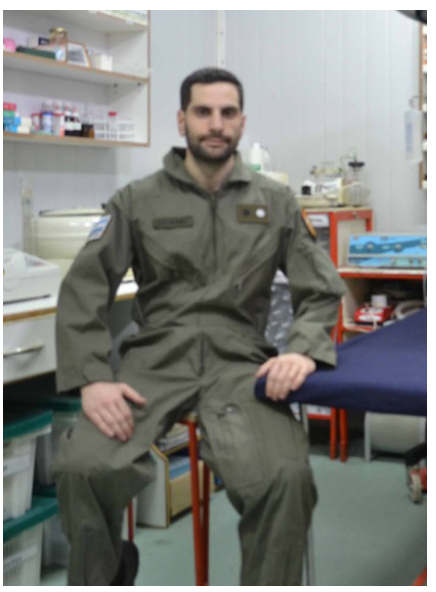

\begin{abstract}
Agustin Folgueira
Médico Argentino de 30 anos, Professor de Neuroanatomia na Universidade de Buenos Aires. Entrou para o exército em 2010 para fazer a residência em Medicina Interna no Hospital Militar de Buenos Aires. Atualmente é o médico responsável pela Base Belgrano II na Antártica. A Base é como uma pequena vila com 18 pessoas,isolada no deserto de gelo e sem possibilidade de evacuação de emergência. Agustin participou do curso de extensão da PUCRS em Space Life Sciences, organizado pelo Centro de Microgravidade, e nos concedeu uma entrevista no final de novembro, onde falou de sua rotina e desafios na Antártica.
\end{abstract}

- Como surgiu a ideia de trabalhar como médico na Base Belgrano II da Argentina?

En el año 2010 ingrese al Ejército, trabajando como médico en el Hospital Militar y especializándome en Medicina Interna, desde ese momento siempre tuve la posibilidad y el deseo de realizar una Campaña Antártica, además me generó mucho entusiasmo la propuesta del Dr. Daniel Vigo, de estudiar los ritmos circadianos.
- Qual a sua rotina na Antártida?

Trabajamos de Lunes a Viernes, de 08:00 a 13:00 y de 15:00 a 19:00 hs, tenemos actividades muy variadas. La base es una pequeña ciudad, tenemos actividades comunitarias: limpieza de la casa, elaboración de agua, mantenimiento de instalaciones y caminos, pintura. Además cada uno tiene sus actividades específicas, mecánicos, carpintero, cocinero, oficial de medio ambiente,

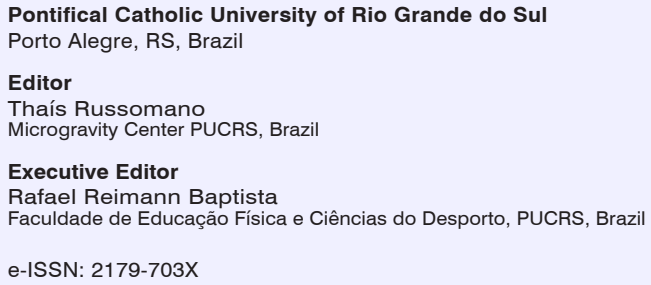

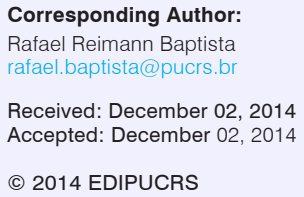


meteorología, radio y los 3 científicos (muy importantes), ellos realizan muchos estudios de atmósfera, ozono, campos magnéticos, radiaciones solares, sismografía, geodesia y meteorología.

Quais são as suas atividades na Base?

Mis actividades específicas son: controles de salud de rutina, atención de consultas médicas, mantenimiento y reparación de la enfermería, tareas de saneamiento, prevención de accidentes y las mediciones del estudio de investigación "Belgrano a Marte".

O que faz no seu tempo livre?

En mi tiempo libre estudio en mi habitación, realizo entrenamiento físico a diario en el gimnasio, aprendo cocina, veo alguna película en la sala de video, algunas veces juego al pool o juego de mesa.

Qual a maior experiência que passou na Antártida?

La convivencia, somos un grupo cerrado de 18 personas en un espacio reducido. Convivir positivamente para cumplir los objetivos es una tarea difícil y muy constructiva, especialmente cuando todos somos muy distintos, tenemos diferentes costumbres y personalidades.

- Quais são os principais desafios de trabalhar neste local?

La Antártida es un lugar inhóspito, frío y ventoso. En nuestra base tenemos temperaturas de $-40^{\circ} \mathrm{C}$ en invierno $y-5^{\circ} \mathrm{C}$ en verano, con vientos de $200 \mathrm{~km} / \mathrm{h}, 4$ meses de noche competa y 4 meses de días completos. Cerca de la base tenemos muchísima grietas ocultas en el hielo, tan peligrosas que una caída puede provocar la muerte. Estas situaciones del medio ambiente, sumado a la imposibilidad de un rescate ante una emergencia médica, las distancias con las familias, las dificultades en las comunicaciones y la convivencia en un lugar confinado presentan un gran desafío, que al superarlo positivamente ayudan a las personas, dando espíritu de solidaridad, tolerancia, reflexión, sacrificio y compañerismo.

- Como ficou sabendo do curso da PUCRS em Space Life Sciences?

Conocía el Centro de Microgravedad de PUCRS por sus publicaciones, específicamente me enteré del curso por el Dr. Daniel Vigo.
Porque escolheu participar do curso?

Me interesó mucho la propuesta, especialmente por los temas abordados y sus experiencia en la investigación en microgravedad. El curso me da mucha ayuda para mi estudio de investigación.

O que acha da iniciativa da PUCRS de integrar alunos de diferentes nacionalidades num único curso a distância?

Ya conocía su forma de trabajo en: Russomano T, et al. The Brazilian Research and Teaching Center in Biomedicine and Aerospace Biomedical Engineering. Hippokratia 2008, 12 (Suppl 1): 32-36

Esta nueva modalidad de curso a distancia en inglés me pareció una excelente iniciativa, para aprender e imitar. Me gustaría poder seguir participando en sus actividades, dado su experiencia, calidad de trabajo y nuestro gran afecto y admiración hacia Brasil.

Qual a relevância do curso para sua carreira profissional?

Aumenta mis conocimientos, aporta nuevas experiencias y la capacidad de conocer nuevos colegas. Me gusta mucho la plataforma virtual del curso y la gran colaboración de los profesiores.

Acredita que o curso pode ser útil para o seu doutorado?

Si, acredita. Además me ayuda mucho en la elaboración del marco teórico y la ampliación de los conocimientos.

- Qual o campo da ciência escolhido por você e sobre o que se trata?

Siempre me interesaron las neurociencias, inicialmente la morfología, actualmente la fisiología, impulsado por mis estudios de los ritmos circadianos.

Como é o contato com a sua família? Você conversa com eles? Como faz para acabar com a saudade?

Yo realizo comunicaciones telefónicas y por mail con mi familia todas las semanas y algunos otros días particulares, pero es mucho más difícil para otras personas de la base que tiene hijos en argentina. Se necesita un buena familia para poder superar el confinamiento. Estamos muy bien en la base, pero todos tenemos ganas de regresar pronto para ver nuestras familias y amigos. 